\title{
DIMENSI METRIK PADA GRAF AMALGAMASI TANGGA SEGITIGA DIPERUMUM HOMOGEN
}

\author{
FIFI FEBRIANTI, LYRA YULIANTI, NARWEN \\ Program Studi S1 Matematika, \\ Fakultas Matematika dan Ilmu Pengetahuan Alam, Universitas Andalas, \\ Kampus UNAND Limau Manis Padang, Indonesia. \\ email : fififebrianti4@gmail.com
}

\begin{abstract}
Abstrak. Misalkan terdapat $G=(V, E)$ suatu graf terhubung dan misal terdapat dua titik $u, v \in V$. Jarak antara $u$ dan $v$ didefinisikan sebagai panjang lintasan terpendek antara $u$ dan $v$ yang dinotasikan dengan $d(u, v)$. Misalkan terdapat himpunan terurut $W \subset V(G)$, dengan $W=\left\{w_{1}, w_{2}, \cdots, w_{k}\right\}$. Misal terdapat titik $v \in V(G)$. Representasi titik $v$ terhadap $W$, dinotasikan $r(v \mid W)$, adalah $k$-vektor
\end{abstract}

$$
r(v \mid W)=\left(d\left(v, w_{1}\right), d\left(v, w_{2}\right), \cdots, d\left(v, w_{k}\right)\right) .
$$

Jika untuk setiap dua titik $u$ dan $v$ di $G$ diperoleh bahwa $r(u \mid W) \neq r(v \mid W)$, maka $W$ dinamakan sebagai himpunan pemisah (resolving set) untuk $G$. Himpunan pemisah yang mempunyai kardinalitas minimum dinamakan himpunan pemisah minimum (minimum resolving set). Banyaknya anggota dari himpunan pemisah minimum ini dinamakan dimensi metrik dari $G$, dinotasikan $\operatorname{dim}(G)$. Graf amalgamasi graf tangga segitiga diperumum homogen adalah graf yang diperoleh dari hasil amalgamasi $m$ buah graf tangga segitiga diperumum yang homogen, lebih sederhana dinotasikan dengan $\left.\operatorname{Amal} \operatorname{Tr}_{n}, v\right\}_{m}$. Pada paper ini dibahas dimensi metrik dari $\operatorname{Amal}_{\left\{T_{n}, v\right\}_{m}}$ dengan $n=3, n=4$ dan $m=2$.

Kata Kunci: Dimensi Metrik, Himpunan pemisah,Representasi, Graf amalgamasi tangga segitiga diperumum homogen

\section{Pendahuluan}

Teori graf merupakan salah satu cabang ilmu matematika yang sangat bermanfaat untuk membantu menyelesaiakan suatu permasalahan dalam kehidupan nyata. Beberapa contoh permasalahan dalam kehidupan sehari-hari yang dapat direpresentasikan sebagai masalah yang berkaitan dengan teori graf, misalnya masalah penjadwalan dengan pewarnaan titik graf, penggambaran struktur organisasi.

Salah satu kajian dalam teori graf adalah dimensi metrik. Istilah dimensi metrik pada teori graf muncul pertama kali pada tahun 1976, yaitu pada artikel yang ditulis oleh F. Harary dan R. A Milter yang berjudul On the metric dimension of a graph $[2]$. 


\section{Landasan Teori}

\subsection{Definisi dan Terminologi Graf}

Suatu graf $G$ didefinisikan sebagai pasangan himpunan $(V(G), E(G))$ dimana dalam hal ini $V(G)$ adalah suatu himpunan titik (vertex) yang tidak kosong dan $E(G)$ adalah himpunan sisi (edge) yang terdiri dari pasangan tak terurut dari titik-titik berbeda dari $V(G)$. Dapat dilihat bahwa $V(G)$ tidak boleh kosong sedangkan $E(G)$ boleh kosong. Jadi suatu graf dimungkinkan tidak mempunyai sisi, tetapi titiknya harus ada, minimal satu. Misalkan $V=\left\{v_{1}, v_{2}, \cdots, v_{n}\right\}$ adalah himpunan titik yang berisi $n$ titik di $G$ dan $E=\left\{e_{1}, e_{2}, \cdots, e_{m}\right\}$ adalah himpunan sisi yang berisi $m$ sisi di $G$. Secara umum, sisi dapat ditulis dengan $v_{i} v_{j}$ atau $v_{j} v_{i}$.

$\operatorname{Jalan}\left(\right.$ walk) dari titik $v_{0}$ ke titik $v_{n}$ di $G$ adalah barisan berhingga titik-titik dan sisi-sisi di $G$ yaitu $v_{0} e_{1} v_{1} e_{2} \cdots e_{k} v_{k}$ sedemikian sehingga untuk $1 \leq i \leq k$, sisi $e_{i}$ adalah $v_{i-1} v_{i} \in E(G)$ untuk $i=1,2, \cdots, n$. Dalam hal ini, $v_{0}$ disebut titik awal (terminal vertex). Jejak (trail) adalah jalan yang melewati setiap sisi yang berbeda. Lintasan (path) adalah jalan dimana titik dan sisi yang dilewati tidak boleh berulang. Panjang lintasan adalah banyaknya sisi yang terdapat pada lintasan tersebut. Jarak antara dua titik $u$ dan $v$, dinotasikan dengan $d(u, v)$, adalah panjang lintasan terpendek dari titik $u$ ke $v$.

Loop adalah suatu sisi yang memiliki titik awal dan titik ujung yang sama. Sisi ganda adalah dua titik yang dihubungkan oleh dua sisi berbeda. Suatu graf dikatakan graf sederhana apabila graf tersebut tidak memuat loop dan sisi ganda. Suatu graf $G$ dikatakan graf terhubung(connected graph) jika untuk setiap pasang titik $u, v \in V(G)$ terdapat suatu lintasan yang menghubungkan $u$ dan $v$. Suatu graf $H$ dikatakan subgraf dari suatu graf G jika $V(H) \subseteq V(G)$ dan $E(H) \subseteq E(G)$. Graf lintasan (path) adalah graf sederhana yang terdiri dari satu lintasan. Graf lintasan dengan $n$ titik dinotasikan dengan $P_{n}$, untuk $n \geq 2$. Graf Lengkap adalah suatu graf yang setiap titiknya saling bertetangga. Graf lingkaran (Cycle) dilambangkan dengan $C_{n}$ dengan $n \geq 3$, adalah suatu graf yang setiap titiknya berderajat dua.

\subsection{Amalgamasi pada Graf}

Definisi 2.1. [3] Untuk $i \in\{1,2, \cdots, t\}, t \in N$. Untuk $t \geq 2$, misalkan $\left\{G_{1}, G_{2}, \cdots, G_{t}\right\}$ kumpulan hingga graf dari graf terhubung dan tak trivial dan $v_{0,1}$ adalah sebuah titik dari graf $G_{i}$ yang dinamakan titik terminal. Graf amalgamasi dinotasikan dengan Amal $\left\{G_{i}, v_{0 i}\right\}_{i=1}^{t}$ adalah suatu graf yang berasal dari graf $G_{1}, G_{2}, \cdots, G_{t}$ dengan cara mengidentifikasi titik-titik terminal dari $\left\{G_{1}, G_{2}, \cdots, G_{t}\right\}$ tersebut sedemikian sehingga $v_{0,1}=v_{0,2}=\cdots=v_{0, t}$.

Mengidentifikasi titik-titik terminal dari setiap graf $G_{i}$ artinya menyatukan titiktitik tersebut sehingga terbentuk sebuah titik baru pada graf $\operatorname{Amal}\left\{G_{i}, v_{0 i}\right\}_{i=1}^{m}$.

\subsection{Graf Amalgamasi Tangga Segitiga yang Diperumum Homogen}

Graf amalgamasi tangga segitiga diperumum homogen adalah graf yang diperoleh dari hasil amalgamasi $m$ buah graf tangga segitiga diperumum yang homogen. Graf 
tangga segitiga diperumum $T r_{n}$ untuk $n \geq 2$ adalah graf yang dibentuk dari $n-1$ buah graf tangga segitiga, yaitu 1-tangga segitiga, 3-tangga segitiga , . ., $(2 n-3)$ tangga segitiga, dan menambahkan sebuah titik yang bertetangga dengan $n$ buah titik pada graf $(2 n-3)$-tangga segitiga. Graf tangga segitiga diperumum $\operatorname{Tr}_{n}$ dengan $n \geq 2$ diilustrasikan pada Gambar 1 [5].
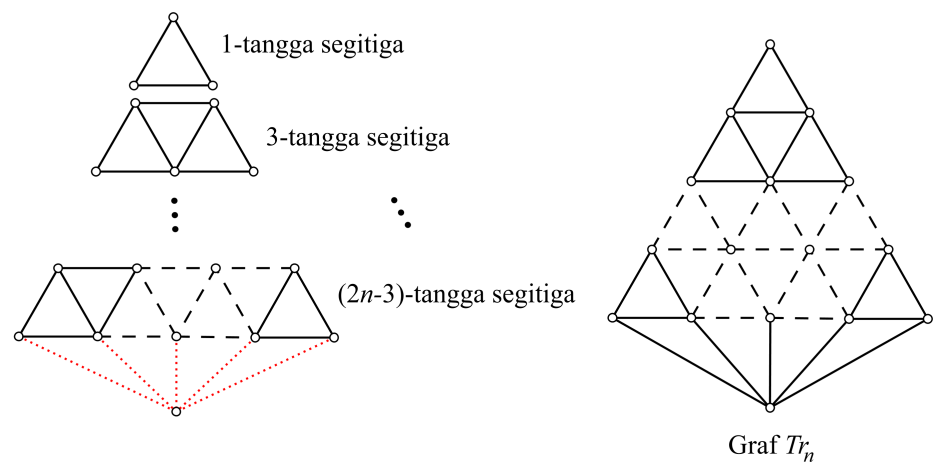

Gambar 1. Graf tangga segitiga diperumum $T r_{n}$

Berdasarkan Definisi 2.1, graf amalgamasi graf tangga segitiga diperumum homogen adalah graf $\operatorname{Amal}\left\{G_{i}, v_{0, i}\right\}_{i=1}^{m}$, dimana setiap $G_{i}$ adalah graf yang sama (homogen) yaitu graf $T r_{n}$ dan $v_{0, i}$ adalah titik terminal dari $G_{i}$, untuk $m, n \in \mathbb{N}$ dengan $n \geq 2$ dan $m \geq 2$.

Misalkan graf $\operatorname{Tr}_{n k}$ adalah graf $T r_{n}$ ke- $k$, untuk $k=1,2, \cdots, m$ dan $m \in \mathbb{N}, i$ menyatakan tingkatan pada graf $T r_{n}$, dan $j$ menyatakan sisi miring pada graf $T r_{n}$. Maka

$$
\begin{aligned}
V\left(T r_{n, k}\right)= & \left\{v_{k}\right\} \cup\left\{v_{k i j} \mid 1 \leq i \leq n, 1 \leq j \leq n-i+1\right\}, \\
E\left(T r_{n, k}\right)= & \left\{v_{k} v_{k 1 j} \mid 1 \leq j \leq n\right\} \\
& \cup\left\{v_{k i j} v_{k i(j+1)} \mid 1 \leq i \leq n-1,1 \leq j \leq n-i\right\} \\
& \cup\left\{v_{k i j} v_{k(i+1) j} \mid 1 \leq i \leq n-j, 1 \leq j \leq n-1\right\} \\
& \cup\left\{v_{k i j} v_{k(i+1)(j-1)} \mid 1 \leq i \leq j-1,2 \leq j \leq n\right\}
\end{aligned}
$$

Dengan mengidentifikasi titik-titik $v_{1}, v_{2}, \cdots, v_{m}$ menjadi titik $v$, dari graf $T r_{n 1}, T r_{n 2}, \cdots, T r_{n k}$, maka untuk setiap $n \geq 2$ dan $m \geq 2$, graf $\left.\operatorname{Amal} \operatorname{Tr}_{n}, v\right\}_{m}$ adalah graf dengan

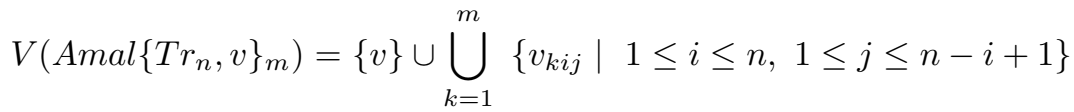

$$
\begin{aligned}
& E\left(\operatorname{Amal}\left\{\operatorname{Tr}_{n}, v\right\}_{m}\right)=\left\{v v_{k 1 j} \mid 1 \leq k \leq m, 1 \leq j \leq n\right\} \\
& \cup\left\{v_{k i j} v_{k i(j+1)} \mid 1 \leq k \leq m, 1 \leq i \leq n-1,1 \leq j \leq n-i\right\} \\
& \cup\left\{v_{k i j} v_{k(i+1) j} \mid 1 \leq k \leq m, 1 \leq i \leq n-j, 1 \leq j \leq n-1\right\} \\
& \cup\left\{v_{k i j} v_{k(i+1)(j-1)} \mid 1 \leq k \leq m, 1 \leq i \leq j-1,2 \leq j \leq n\right\}
\end{aligned}
$$




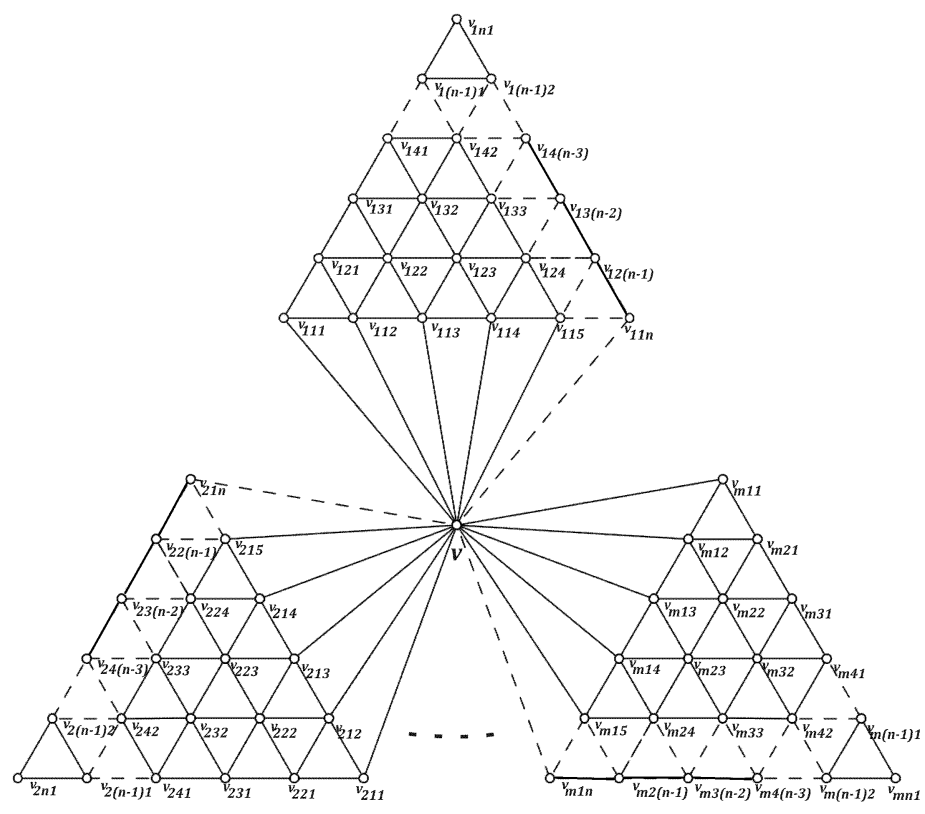

Gambar 2. Graf Amal $\left\{T r_{n}, v\right\}_{m}$ dengan $m \geq 2$ dan $n \geq 2$.

\subsection{Dimensi Metrik}

Misalkan terdapat $G=(V, E)$ suatu graf terhubung dan misal terdapat dua titik $u, v \in V$. Jarak antara $u$ dan $v$ didefinisikan sebagai panjang lintasan terpendek antara $u$ dan $v$ yang dinotasikan dengan $d(u, v)$. Misalkan terdapat himpunan terurut $W \subset V(G)$, dengan $W=\left\{w_{1}, w_{2}, \cdots, w_{k}\right\}$. Misal terdapat titik $v \in V(G)$. Representasi titik $v$ terhadap $W$, dinotasikan $r(v \mid W)$, adalah $k$-vektor

$$
r(v \mid W)=\left(d\left(v, w_{1}\right), d\left(v, w_{2}\right), \cdots, d\left(v, w_{k}\right)\right) .
$$

Jika untuk setiap dua titik $u$ dan $v$ di $G$ diperoleh bahwa $r(u \mid W) \neq r(v \mid W)$, maka $W$ dinamakan sebagai himpunan pemisah (resolving set) untuk $G$. Himpunan pemisah yang mempunyai kardinalitas minimum dinamakan himpunan pemisah minimum (minimum resolving set). Banyaknya anggota dari himpunan pemisah minimum ini dinamakan dimensi metrik dari $G$, dinotasikan $\operatorname{dim}(G)[1]$.

Teorema 2.2. [1] Misal $G$ adalah graf terhubung dengan banyak titik $n \geq 2$, maka $\operatorname{dim}(G)=1$ jika dan hanya jika $G=P_{n}$.

Teorema 2.3. [4] Misalkan $\left\{G_{1}, G_{2}, \cdots, G_{n}\right\}$ kumpulan terbatas graf dan $v_{0 i}$ adalah titik awal dari $G_{i}, i=1,2, \cdots, n$. Jika $G$ adalah amalgamasi dari $G_{1}, G_{2}, \cdots, G_{n}$, Amal $\left\{G_{i}, v_{0 i}\right\}$, maka

$$
\sum_{i=1}^{n} \operatorname{dim}\left(G_{i}\right)-n \leq \operatorname{dim}(G) \leq \sum_{i=1}^{n} \operatorname{dim}\left(G_{i}\right)+n-1 .
$$




\section{Dimensi Metrik dari Graf Amalgamasi Tangga Segitiga Diperumum Homogen}

Pada bab ini akan dibahas mengenai dimensi metrik dari graf amalgamasi tangga segitiga diperumum homogen $\operatorname{Amal}\left\{\operatorname{Tr}_{n}, v\right\}_{2}$ untuk $n=3, n=4$ dan $m=2$.

Teorema 3.1. Misalkan Amal $\left\{\mathrm{Tr}_{n}, v\right\}_{2}$ adalah graf amalgamasi tangga segitiga yang diperumum homogen dengan $n=3$ dan $m=2$. Maka

$$
\operatorname{dim}\left(\operatorname{Amal}_{\left.\left\{T_{3}, v\right\}_{2}\right)=3 .}\right.
$$

Bukti. Andaikan $W=\{a, b\}, a \neq b$, dimana $a$ dan $b$ adalah sebarang titik-titik yang terdapat pada graf $A \operatorname{mal}\left\{\operatorname{Tr}_{3}, v\right\}_{2}$. Himpunan $W$ tidak akan memberikan representasi yang berbeda, karena terdapat paling sedikit dua titik mempunyai representasi yang sama, yaitu dua titik yang jaraknya ke titik $v$ sama. Karena himpunan $W$ tidak memberikan representasi yang berbeda, maka diperoleh bahwa

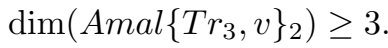

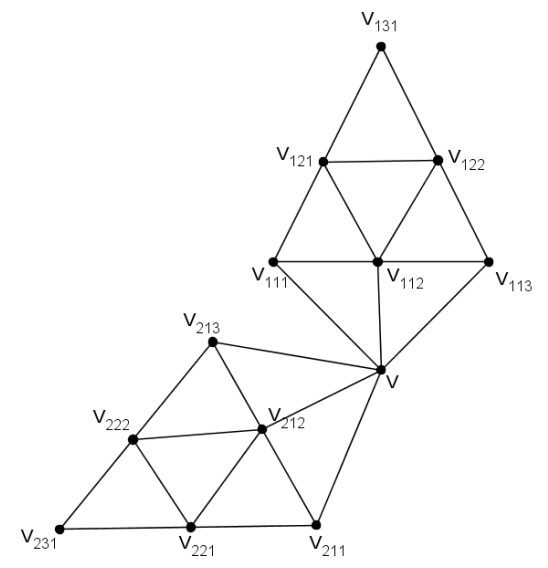

Gambar 3. Graf Amal $\left\{\operatorname{Tr}_{3}, v\right\}_{2}$.

Selanjutnya misalkan $W=\left\{v_{111}, v_{122}, v_{211}\right\}$. Representasi semua titik pada graf $A \operatorname{mal}\left\{\operatorname{Tr}_{3}, v\right\}_{2}$ terhadap $W$ adalah

$$
\begin{array}{rlrl}
r(v \mid W) & =(1,2,1) & & \\
r\left(v_{111} \mid W\right) & =(0,2,2) & & r\left(v_{211} \mid W\right)=(2,3,0) \\
r\left(v_{112} \mid W\right) & =(1,1,2) & & r\left(v_{212} \mid W\right)=(2,3,1) \\
r\left(v_{113} \mid W\right) & =(2,1,2) & & r\left(v_{213} \mid W\right)=(2,3,2) \\
r\left(v_{121} \mid W\right) & =(1,1,3) & r\left(v_{221} \mid W\right)=(3,4,1) \\
r\left(v_{122} \mid W\right) & =(2,0,3) & r\left(v_{222} \mid W\right)=(3,4,2) \\
r\left(v_{131} \mid W\right) & =(2,1,4) & r\left(v_{231} \mid W\right)=(4,5,2),
\end{array}
$$


Dari semua representasi di atas terlihat bahwa representasi setiap titik berbeda. Karena memberikan representasi yang berbeda dengan $|W|=3$, maka batas $\operatorname{dim}\left(A \operatorname{mal}\left\{\operatorname{Tr}_{3}, v\right\}_{2}\right)$ adalah 3. Karena batas atas $\operatorname{dim}\left(A \operatorname{mal}\left\{\operatorname{Tr}_{3}, v\right\}_{2}\right)$ adalah 3 maka diperoleh $\operatorname{dim}\left(A \operatorname{mal}\left\{\operatorname{Tr}_{3}, v\right\}_{2}\right) \leq 3$, sehingga $\operatorname{dim}\left(A \operatorname{mal}\left\{\operatorname{Tr}_{3}, v\right\}_{2}\right)=3$.

Teorema 3.2. Misalkan Amal $\left\{\operatorname{Tr}_{n}, v\right\}_{2}$ adalah graf amalgamasi tangga segitiga

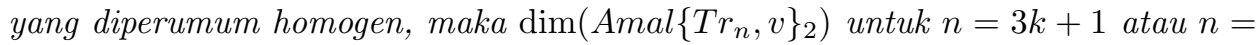
$3 k-1$ dengan $k=1$ adalah

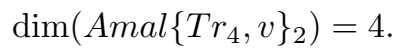

Bukti. Andaikan $W=\{a, b, c\}, a \neq b \neq c$, dimana $a, b$ dan $c$ adalah titik-titik yang terdapat pada graf $A \operatorname{mal}\left\{\operatorname{Tr}_{4}, v\right\}_{2}$. Himpunan $W$ tidak memberikan representasi yang berbeda, karena terdapat paling sedikit dua titik mempunyai representasi yang sama, yaitu dua titik yang jaraknya ke titik $v$ sama. Karena himpunan $W$ tidak memberikan representasi yang berbeda, maka diperoleh bahwa

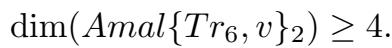

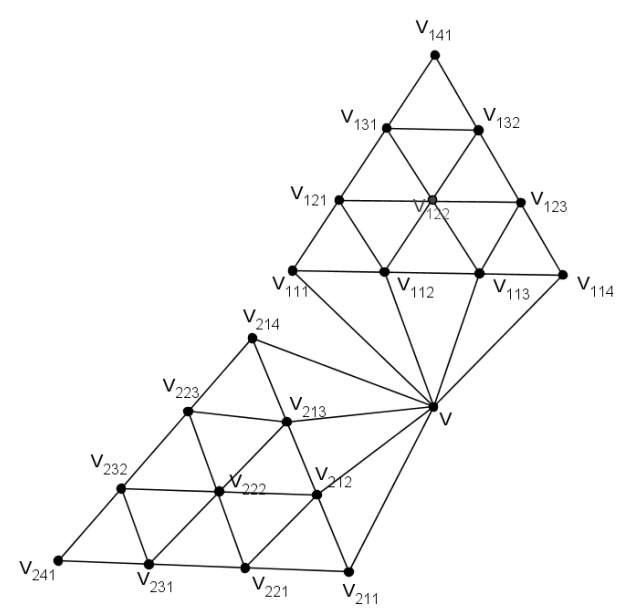

Gambar 4. Graf Amal $\left\{\operatorname{Tr}_{4}, v\right\}_{2}$.

Selanjutnya ambil $W=\left\{v_{111}, v_{122}, v_{211}, v_{222}\right\}$. Representasi semua titik pada graf $A$ mal $\left\{\mathrm{Tr}_{4}, v\right\}_{2}$ terhadap $W$ adalah

$$
\begin{aligned}
r(v \mid W) & =(1,2,1,2) & & \\
r\left(v_{111} \mid W\right) & =(0,2,2,3) & & r\left(v_{211} \mid W\right)=(2,3,0,2) \\
r\left(v_{112} \mid W\right) & =(1,1,2,3) & & r\left(v_{212} \mid W\right)=(2,3,1,1) \\
r\left(v_{113} \mid W\right) & =(1,1,2,3) & & r\left(v_{213} \mid W\right)=(2,3,2,1) \\
r\left(v_{114} \mid W\right) & =(2,2,2,3) & & r\left(v_{214} \mid W\right)=(2,3,2,2)
\end{aligned}
$$




$$
\begin{array}{ll}
r\left(v_{121} \mid W\right)=(1,1,3,4) & r\left(v_{221} \mid W\right)=(3,4,1,1) \\
r\left(v_{122} \mid W\right)=(2,0,3,4) & r\left(v_{222} \mid W\right)=(3,4,2,0) \\
r\left(v_{123} \mid W\right)=(3,1,3,4) & r\left(v_{223} \mid W\right)=(3,4,3,1) \\
r\left(v_{131} \mid W\right)=(2,1,4,5) & r\left(v_{231} \mid W\right)=(4,5,2,1) \\
r\left(v_{132} \mid W\right)=(3,1,4,5) & r\left(v_{232} \mid W\right)=(4,5,3,1) \\
r\left(v_{141} \mid W\right)=(3,2,5,6) & r\left(v_{241} \mid W\right)=(5,6,3,2) .
\end{array}
$$

Dari semua representasi diatas dapat dilihat bahwa representasi setiap titik berbeda. Karena memberikan representasi yang berbeda dengan $|W|=4$, maka batas

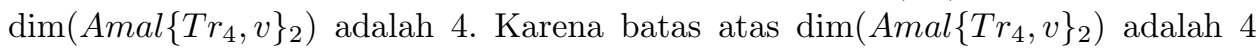
maka diperoleh $\operatorname{dim}\left(\operatorname{Amal}\left\{\operatorname{Tr}_{n}, v\right\}_{2}\right) \leq 4$, sehingga $\operatorname{dim}\left(\operatorname{Amal}\left\{\operatorname{Tr}_{4}, v\right\}_{2}\right)=4$.

\section{Kesimpulan}

Pada tugas akhir ini telah dibahas dimensi metrik dari graf $\operatorname{Amal}\left\{\operatorname{Tr}_{n}, v\right\}_{2}$. Graf tangga segitiga diperemum dinotasikan dengan $\operatorname{Tr}_{n}$ untuk $n \geq 2$ adalah graf dengan himpunan titik $V\left(T r_{n}\right)=\{v\} \cup\left\{v_{i j} \mid 1 \leq i \leq n, 1 \leq j \leq n-i+1\right\}$ dan himpunan sisi $E\left(T r_{n}\right)=\left\{v v_{1 j} \mid 1 \leq j \leq n\right\} \cup\left\{v_{i j} v_{i(j+1)} \mid 1 \leq i \leq n-1,1 \leq j \leq\right.$ $n-i\} \cup\left\{v_{i j} v_{(i+1) j} \mid 1 \leq i \leq n-j, 1 \leq j \leq n-1\right\} \cup\left\{v_{i j} v_{(i+1)(j-1)} \mid 1 \leq i \leq j-1,2 \leq\right.$ $j \leq n\}$. Graf amalgamasi graf tangga segitiga diperumum homogen adalah graf yang diperoleh dari hasil amalgamasi $m$ buah graf tangga segitiga diperumum yang homogen, lebih sederhana dinotasikan dengan $\operatorname{Amal}\left\{\operatorname{Tr}_{n}, v\right\}_{m}$. Pada penelitian ini diambil kasus $n=3, n=4$ dan $m=2$.

Diperoleh dimensi metrik dari graf $A \operatorname{mal}\left\{\operatorname{Tr}_{n}, v\right\}_{2}$ sebagai berikut :

$$
\operatorname{dim}\left(\operatorname{Amal}\left\{\operatorname{Tr}_{n}, v\right\}_{2}\right)=\left\{\begin{array}{l}
3, \text { jika } n=3 \\
4, \text { jika } n=4
\end{array}\right.
$$

\section{Ucapan Terima kasih}

Penulis mengucapkan terimakasih kepada Ibu Dr. Des Welyyanti, Bapak Dr. Admi Nazra, Ibu Nova Noliza Bakar, M.Si yang telah memberikan kritikan dan saran sehingga makalah ini dapat diselesaikan dengan baik.

\section{Daftar Pustaka}

[1] Chartrand, G., dkk. 2000. Resolvability in graphs and the metric dimension of a graph. Discrete Applied Mathematics. 105: 99 - 113.

[2] Harary, F., R.A Melter. 1976. On the metric dimension of a graph. Ars Combin. $2: 191-195$

[3] Iswadi, H., E. T. Baskoro, A. N. M. Salman dan R. Simanjuntak. 2010. The Resolving Graph of Amalgamtion of Cycles, Utilitas Matematica 83: 121 - 132

[4] Simanjuntak, R., Saladin Uttunggadewa, and Suhadi Wido Saputro. Metric Dimension of Amalgamation of Graphs, arXiv:1312.0191v2[math.CO] (2013)

[5] Yulianti, L., Narwen, Fitrianda, S., On The Rainbow Connection Number of The Generalized Triangle Ladder Graphs, submitted 